\title{
Increase of Extracellular Corticotropin-Releasing Factor-Like Immunoreactivity Levels in the Amygdala of Awake Rats during Restraint Stress and Ethanol Withdrawal as Measured by Microdialysis
}

\author{
Emilio Merlo Pich, ${ }^{a}$ Marge Lorang, Mark Yeganeh, Fernando Rodriguez de Fonseca, ${ }^{b}$ Jacob Raber, George F. \\ Koob, and Friedbert Weiss
}

Department of Neuropharmacology, The Scripps Research Institute, La Jolla, California 92037

\begin{abstract}
Previous research has suggested a role for corticotropinreleasing factor (CRF) in the anxiogenic effects of stressful stimuli and ethanol withdrawal. This hypothesis was explored in a series of experiments using intracranial microdialysis to monitor CRF-like immunoreactivity (CRF-IR) in the extracellular compartment of the rat amygdala. The synaptic origin of CRF-IR release in the amygdala was determined in vitro by assessing the $\mathrm{Ca}^{2+}$ dependency of 4-aminopyridine stimulated CRF-IR release from tissue preparations of rat amygdala. In vivo experiments were performed in awake rats after the placement of microdialysis probes in the amygdala. In the first experiment, transient restraint stress $(20 \mathrm{~min})$ produced an increase of CRF-IR release (basal levels, $1.19 \pm 0.15 \mathrm{fmol} / 50 \mu$ l; stress levels, $4.54 \pm 1.33 \mathrm{fmol} / 50 \mu \mathrm{l} ; p<0.05)$ that returned to basal values within $1 \mathrm{hr}$. When 4-aminopyridine $(5 \mathrm{~mm})$ was added to the perfusion medium, it consistently increased CRF-IR release $(4.83 \pm 0.92 \mathrm{fmol} / 50 \mu \mathrm{l}, p<0.05)$. In the second experiment, CRF-IR release was measured during ethanol withdrawal in rats previously maintained for 2-3 weeks on a liquid diet containing ethanol (8.5\%). Basal CRF-IR levels were $2.10 \pm 0.43 \mathrm{fmol} / 50 \mu \mathrm{l}$ in ethanol exposed rats and $1.30 \pm 0.19 \mathrm{fmol} / 50 \mu \mathrm{l}$ in control rats. During withdrawal, a progressive increase of CRF-IR levels over time was observed, reaching peak values at 10-12 $\mathrm{hr}$ after the onset of withdrawal $(10.65 \pm 0.49 \mathrm{fmol} / 50 \mu \mathrm{l}$ vs $1.15 \pm 0.30 \mathrm{fmol} / 50 \mu \mathrm{l}$ of control rats, $p<0.01$ ). Since the peak of CRF-IR release corresponded to the time of appearance of anxiogenic behavioral effects in rats, the present data lend further support to the hypothesis that the CRF-IR system in the amygdala participates in the media-
\end{abstract}

\footnotetext{
Received Jan. 4, 1995; revised March 20, 1995; accepted april 3, 1995.

This is publication No. 8622-NP from the Scripps Research Institute. This work was supported in part by grant AA07348 (F.W.), AA08459 (G.F.K.), Alcohol Center Grant AA06420 (Dr. F. E. Bloom, director), the National Institute of Alcohol Abuse and Alcoholism (NIAAA), by Grant DA084226 (F.W.), the National Institute of Drug Abuse (NIDA), and Progetto Finalizzato Invecchiamento (C.N.R.) cp. 953559 (E.M.P.). We thank Dominique Talabot-Ayer for skillful technical assistance.

Correspondence should be addressed to Emilio Merlo Pich, M.D., Department of Neurobiology, Glaxo Institute for Molecular Biology, 14 chemin de fer, 1228 Plan-les-Ouates, Geneva, Switzerland.

aResearch fellow from the Department of Internal Medicine, Universily of Modena, Italy.

Research fellow of the Foundation Jaime del Amo, Universidad Computensc, Madrid, Spain.

Copyright (C) 1995 Society for Neuroscience $0270-6474 / 95 / 155439-09 \$ 05.00 / 0$
}

tion of the emotional component of the response to exogenous or endogenous stressful stimuli.

[Key words: corticotropin-releasing factor, Intracranlal microdialysis, 4-aminopyridine, central amygdaloid nucleus, stress, rat, ethanol withdrawal]

Converging lines of evidence suggest that corticotropin-releasing factor (CRF), a hypophysiotropic peptide of 41 amino acids isolated from bovine hypothalamus (Vale et al., 1981), participates in the mediation of behavioral responses to stress in mammals (Koob and Bloom, 1985; Dunn and Berridge, 1990; Nemeroff, 1991; Koob et al., 1993). High densities of CRF immunoreactive perikarya and terminals are present in limbic brain structures (Swanson et al., 1983; Sakanaka et al., 1986; Gray, 1990). CRF binding sites (De Souza et al., 1987; Hauger et al., 1987) and receptors (Perrin et al., 1993) are also widely distributed throughout the CNS. Although hypothalamic CRF is known to play a major role in neuroendocrine adaptation to stress ( $\mathrm{Ri}$ vier et al. 1982; Antoni, 1986; Plotsky, 1991), the role of CRF in specific extrahypothalamic regions of the brain is not clear yet. Changes of CRF-like immunoreactivity (CRF-IR) tissue levels (Chappel et al., 1986) and CRF gene expression (Imaki et al., 1991) are observed following transient or chronic stress in several hypothalamic and limbic structures, indirectly suggesting a response of CRF neurons to stress.

Exogenous administration of CRF induces physiological and behavioral effects that resemble those produced by stress. Intracerebroventricular (i.c.v.) injections of CRF increase the firing of locus coeruleus neurons (Valentino and Foote, 1988), increase peripheral sympathetic outflow (Brown et al., 1982) and respiratory rate (Bohemer et al., 1990), and produce proconflict or "anxiogenic-like" effects in a variety of paradigms of emotionality in rodents (Britton et al., 1985; Dunn and File, 1987; Takahashi et al., 1989). Consistent with these observations, central injections of CRF antagonists block the behavioral effects of either exogenously administered CRF, stress, or conditioned fear (Britton et al., 1986; Kalin et al., 1988; Swerdlow et al., 1989; Liang et al., 1992a; Menzaghi et al., 1994).

Several of the stress-like responses associated with CRF administration can be mimicked by stimulating the central amygdaloid nucleus $(\mathrm{Ce})$, a structure that plays a role in orchestrating various aspects of the emotional output (Swanson and Mogenson, 1981; Le Doux et al., 1988; Davis, 1992). Electrical stimulation of the $\mathrm{Ce}$ increases heart rate, blood pressure, peripheral sympathetic outflow, respiratory rate, and hypothalamo-pitui- 
tary-adrenal (HPA) axis activity, and produce behavioral effects similar of those seen in conditioned fear (Davis, 1986; Dunn and Whitener, 1986; Iwata et al., 1987; Le Doux et al., 1988). Consistent with these observations, lesions of the $\mathrm{Cc}$ attenuatc the conditioned fear response (Sananes and Davis, 1992) and produce anti-conflict effects (Shibata et al., 1989). Since a rich plexus of CRF-containing terminals and neurons projecting to the brainstem is present in the Ce (Gray and Magnuson, 1987), it has been suggested that CRF in the amygdala participates in the mediation of the increased emotionality produced by exposure to stressors.

Prolonged increase in emotionality and HPA axis activation that resemble the effects of stress have been also described during ethanol withdrawal (Freund, 1969; Tabakoff et al., 1978; De Sota et al., 1985). In spite of the evidence suggesting a role of CRF in the ethanol withdrawal syndrome (Ehlers and Chaplin, 1987; Rivier et al., 1990; Baldwin et al., 1991), direct evidence on CRF release in the amygdala during exposure to stress or ethanol withdrawal is still lacking.

Recently, a microdialysis procedure to measure in vivo extracellular levels of CRF-IR in freely moving rats was developed (Merlo Pich et al., 1993). In the present work, this method was used to investigate the effects of restraint stress and ethanol withdrawal on CRF-IR release from the amygdala of awake rats.

\section{Materials and Methods}

Animals. Fifty-five male Wistar rats (Charles River), weighing 200-225 $\mathrm{gm}$ at the beginning of the experiments, were housed in groups of three in standard rat cages in a humidity and temperature $\left(22^{\circ} \mathrm{C}\right)$ controlled vivarium with $12 / 12 \mathrm{hr}$ L/D cycle (lights on at $1900 \mathrm{hr}$ ). Immediately after surgery or at the beginning of the experiments involving liquid diet consumption, the rats were caged individually. Food and water were provided ad libitum for the animals included in experiments 1 and 2, whereas nutritionally balanced liquid diets were used in experiment 3 , as described below.

Dissection of amygdala for in vitro experiments. Rats were sacrificed by decapitation between $1000 \mathrm{hr}$ and $1100 \mathrm{hr}$, their brain rapidly removed, and placed in a brain slicer (San Diego Instruments, San Diego, CA). A $3 \mathrm{~mm}$ thick coronal slice was cut, starting at $1.8 \mathrm{~mm}$ posterior to bregma (Paxinos and Watson, 1986). The amygdaloid regions were dissected out bilaterally from the slice under a low-magnification microscope by a vertical cut tangential to the external capsule and a diagonal cut along the medial border of the ipsilateral optic tract, as previously described (Raber et al., 1994). Amygdaloid regions were then placed on a Brinkmann tissue chopper to obtain $300 \mu \mathrm{m}$ slices. Minced amygdaloid regions were placed in tubes containing balanced Earle's salt solution (GIBCO, Gaithersburg, MD) supplemented with $0.1 \%$ bovine serum albumin (BSA, Pentex, Miles Inc., Kankakee, IL), $60 \mu \mathrm{g} /$ $\mathrm{ml}$ ascorbic acid (Aldrich, Milwaukee, WI) $0.54 \mathrm{mg} / \mathrm{kg}$ glucose, $20 \mathrm{~mm}$ bacitracin, $1 \mu \mathrm{M}$ phenylmethylsulfonyl fluoride (Sigma, St. Louis, MO), and $200 \mathrm{kIU} / \mathrm{ml}$ aprotinin (Boehringer-Mannheim, Indianapolis, IN). Slices of the whole amygdaloid regions were incubated at $37^{\circ} \mathrm{C}$ under $\mathrm{O}_{2} / \mathrm{CO}_{2}(95: 5 \%)$ or $60-80 \mathrm{~min}$ before starting the experiment.

Surgery for in vivo experiments with microdialysis. Seven days before the microdialysis experiments, rats were anesthetized (1\% halothane in $\mathrm{O}_{2} / \mathrm{CO}_{2}, 95: 5 \%$ ) and placed in a stereotaxic apparatus (David Kopf Instruments, Tujunga, CA). A guide cannula (CMA/10, Bioanalytical Systems, West Lafayette, IN) was unilaterally implanted $7 \mathrm{~mm}$ above the final location of the microdialysis probe tip, and secured with stainless steel skull screws and dental cement. Final stereotaxic coordinates with respect to the microdialysis probe tip were $2.6 \mathrm{~mm}$ posterior to bregma, $4.2 \mathrm{~mm}$ lateral to the midline, $-8.7 \mathrm{~mm}$ below dura (Paxinos and Watson, 1986).

Microdialysis apparatus and perfusion media. Experiments were performed using commercially available microdialysis probes (CMA/10, external diameter of $0.5 \mathrm{~mm}, 2 \mathrm{~mm}$ dialysis membrane tip, molecular cutoff of 20,000 Da). Perfusion medium was loaded into Hamilton syringes operated by a pulseless microinfusion pump (CMA/100). A liquid switch (CMA/110) was used to permit rapid changes of the perfusion medium. Perfusate was collected in polyethylene tubes kept in ice during the perfusion interval ( $20 \mathrm{~min}$ ). Perfusion fractions were frozen on dry ice immediately after collection and stored at $-70^{\circ} \mathrm{C}$ until radioimmunoassay. Before each experiment, microdialysis probes were perfused at room temperature with artificial cerebrospinal fluid containing $1 \%$ BSA to saturate nonspecific binding sites for peptides within the perfusion system.

The basic perfusion medium consisted of artificial cerebrospinal fluid (ACSF) containing $\mathrm{NaCl}(149.0 \mathrm{mM}), \mathrm{KCl}(3.7 \mathrm{~mm}), \mathrm{MgCl}_{2}(0.9 \mathrm{mM})$, $\mathrm{CaCl}_{2}(1.2 \mathrm{mM}), \mathrm{NaH}_{2} \mathrm{PO}_{4}(1.2 \mathrm{~mm})$, and BSA (1\%). The ACSF (pH 7.4) was filtered sterile with nylon filters (Gelman Acrodisc 4192, Ann Arbor, MI). This medium was used for rinsing the probe, and perfusion of probes implanted into the animals during periods when CRF levels were not monitored. The perfusion medium used for measuring CRF was prepared by adding specific anti-CRF serum (rC70 or rC69, kindly provided by $W$. Vale) to ACSF at a dilution of 1:80,000. Anti-CRF serum was added because previous observations have shown that the addition of a specific, well-characterized anti-CRF rabbit serum to the perfusion medium can improve the recovery of CRF-IR (Merlo Pich et al., 1993). At the end of each experiment, an aliquot of remaining perfusion medium containing anti-CRF serum was frozen together with the collected fractions, and stored at $-70^{\circ} \mathrm{C}$. This medium was then used in the construction of the standard curve of the radioimmunoassay.

$C R F$ radioimmunoassays. Detection and quantification of CRF was adapted from Vale et al. (1983). This procedure of CRF measurement is based on competitive binding radioimmunoassay, and was validated with independent HPLC studies. However, in our study, no data verifying of the identity of the immunoreactivity arc presented, due to the low amounts recovered by the experimental techniques we used. Therefore, the measurements are reported as CRF-like immunoreactivity (CRF-IR)

The CRF radioimmunoassay standard method was employed to measure the concentrations of CRF-IR released from amygdaloid region tissue in vitro, as previously described (Smith et al., 1986; Calogero et al., 1989)

This procedure has been extended to microdialysis applications in a series of in vitro and in vivo validations (Merlo Pich et al., 1993). Briefly, the concentration of specific anti-CRF serum within the perfusion medium was calculated in order to optimize the radioimmunoassay for CRF. For each experiment standard curves were prepared in duplicate using $50 \mu \mathrm{l} /$ tube of the same perfusion medium containing antiCRF serum used for microdialysis probe perfusion and fraction collection. Final anti-CRF serum dilution was 1:800,000, and the final incubation volume was $500 \mu \mathrm{l} /$ tube. Standards and samples were incubated in borosilicate glass tubes for $24 \mathrm{hr}$ at $+4^{\circ} \mathrm{C}$ before addition of 16,000 $\mathrm{cpm} /$ tube of the tracer, [ ${ }^{[25} \mathrm{I}_{-}$-Tyr $\left.{ }^{\circ}\right] \mathrm{rCRF}$ (DuPont/NEN, Boston, MA) diluted in normal rabbit serum (Peninsula, Belmont, CA). A second incubation of $24 \mathrm{hr}$ was followed by precipitation of the antigen-antiserum complex with pretitrated goat anti-rabbit antiserum (Peninsula), polyethylene glycol 8000 , and $30 \mathrm{~min}$ centrifugation at $3000 \times \mathrm{g}$. After decanting the supernatant, residual radioactivity was counted in each tube using a gamma-counter (APEX10, ICN Biomedicals, Costamesa, CA). A logistic four-parameter model was used for interpolation of standard curves. Sensitivity of the assay was $0.35 \mathrm{fmol} / \mathrm{tube}$ or less.

Verification of microdialysis probe placement. The day after the experiment, rats were deeply anesthetized with halothane, and microdialysis probes were gently removed and inspected for viability. The animals were then decapitated, the brain dissected out, and immediately frozen on dry ice. Unfixed brains were cut on a cryostat.

The brain of one group of rats was cut in thin sections $(20 \mu \mathrm{m})$, postfixed in $4 \%$ paraformaldehyde for 1 min, and stained with cresyl violet for rostrocaudal analysis of probe trace location within the amygdala. Since the anatomical plane of cutting was different from the plane used for stereotaxic guide cannula implantation, the localization of the active zone of microdialysis probe within the amygdala was obtained by inspecting various adjacent sections. The analysis started from the more caudal level that displayed the deepest lesion trace produced by the microdialysis probe, corresponding to the location of the probe tip. Rostrocaudal and dorsoventral location of probes active zone in each rat brain was identified by selecting the section with a trace positioned at approximately $1 \mathrm{~mm}$ distance from the tip. The rostrocaudal levels of this section was attributed using a stereotaxic atlas (Paxinos and Watson, 1986), and represented as a $2 \mathrm{~mm}$ segment on a semianatomical scheme of the same stereotaxic level.

In a second group of rats, an alternative approach was used to eval uate the anatomical probe location in the rat brains. Thick sections ( 200 
$\mu \mathrm{m}$ ) were collected and postfixed in $4 \%$ paraformaldehyde for at least $1 \mathrm{hr}$. After rinsing with PBS, wet sections were mounted on slides, put on a negative carrier of a photographic enlarger, and projected onto the easel to obtain "negative" photographic prints. Adjacent sections were also cut and stained with cresyl violet to provide additional information about the anatomical localization of the microdialysis probe tip. The location of the active zone of the microdialysis probes was then identified as described above.

Diet, ethanol administration, and blood alcohol level determination. Seventeen rats selected for experiment 3 were maintained on a nutritionally balanced liquid diet consisting of a Sustacal (Mead Johnson, Evansville, IN) base supplemented with vitamins (ICN Nutritional Biochemicals, Aurora; $0.3 \mathrm{~g} / 100 \mathrm{ml}$ ) and minerals (ICN Nutritional Biochemicals; $0.5 \mathrm{~g} / 100 \mathrm{ml}$ ) as previously described (Baldwin et al., 1991). Ethanol $(8.5 \% \mathrm{v} / \mathrm{v})$ was added to the liquid diet of experimental rats. Control diet was made equicaloric by adding sucrose (Sigma). Both control and ethanol liquid diets were given for 2-3 weeks, and the diets were available ad libitum. The volume of diet consumed was measured each morning. A "pair-feeding" procedure was instituted for control rats by keeping the volume of available control diet equal to the volume of ethanol-containing diet consumed by the rats of the ethanol group on the previous day. The effect of this diet regimen on body weight was monitored regularly.

Blood alcohol levels (BAL) were measured in each rat $10 \mathrm{~d}$ after the beginning of the ethanol diet exposure, and $3 \mathrm{~d}$ before the experiment. Blood $(0.5 \mathrm{ml})$ was taken from the tail, collected into $4 \mu \mathrm{l}$ heparin $(1000$ USP units $/ \mathrm{ml}$ ), and centrifuged for $5 \mathrm{~min}$ at $10,000 \mathrm{rpm}$. 'The plasma was acid extracted and alcohol content was determined using the NAD/ ADH method (Sigma). Rats were included into the experimental group when the BAL measured on the last sampling day was higher than 100 $\mathrm{mg} \%$.

Experiment 1: in vitro measurements of $C R F-I R$ release from amygdala. In vitro experiments were performed according to the method of Calogero et al. (1989), with modification. The experiment was conducled at $37^{\circ} \mathrm{C}$ under $\mathrm{O}_{2} / \mathrm{CO}_{2}(95: 5 \%)$, and consisted of serial passage of the minced tissue through different wells of a 48-multiwell plate (Costar, Cambridge, MA) previously precoated with incubation buffer containing 1\% BSA. Each well contained $700 \mu \mathrm{l}$ medium, and tissue minces were passed through wells at $20 \mathrm{~min}$ interval. At the end of each incubation interval the tissue was removed and placed on the next well for the following $20 \mathrm{~min}$ interval. Immediately after removing the tissue, the incubation medium was collected in tubes, frozen on dry ice, and stored at $-70^{\circ} \mathrm{C}$ until CRF radioimmunoassay. A set of preliminary experiments indicated that stabilization of spontaneous CRF-IR release occurs between 80 and 100 min after the beginning of the experiment. The levels of CRF-IR measured in the following incubation interval (100-120 min) was considered the reference basal value for comparison with the stimulated levels. Stimulation was performed in the subsequent interval (120-140 min) incubating the sections in medium containing the $\mathrm{K}^{+}$-channel blocker 4-aminopyridine. A dose-response curve was obtained by incubating minced amygdala with 4-aminopyridine at concentrations of $0.1,1.0$, or $10.0 \mathrm{~mm}$. The $\mathrm{Ca}^{2+}$-dependency of CRF-IR release produced by 4 -aminopyridine $(1.0 \mathrm{~mm})$ was studied by incubating the tissue with the $\mathrm{Ca}^{2+}$ channel blocker $\mathrm{CoCl}_{2}(10 \mathrm{~mm})$. Incu bation with $\mathrm{CoCl}_{2}$ begun during the interval before exposure to 4-aminopyridine. Each experimental group consisted of amygdala minces collected from five to six animals, each tube containing slices from a single animal.

Experiment 2: effects of restraint stress on CRF-IR release from the amygdala. This experiment was performed in the home cage of seven rats previously implanted with a guide cannula. Microdialysis probes were slowly inserted $12 \mathrm{hr}$ prior to the start of sampling and secured in the guide cannula under brief, shallow halothane anesthesia. During this period, the probe was perfused with ACSF at a flow rate of $0.7 \mu \mathrm{l} / \mathrm{min}$. Onc hour bcforc sampling, the perfusion medium was changed to a freshly prepared medium containing anti-CRF serum, and the flow rate was increased to $3.0 \mu \mathrm{l} / \mathrm{min}$. This flow rate was previously shown to yield optimum recovery (Merlo Pich et al., 1993). Fractions were collected every $20 \mathrm{~min}$, at a volume of approximately $60 \mu \mathrm{l}$. After a period of basal collection (five to six samples), animals were restrained for 20 min by immobilizing their paws. At the end of the stress period rats were returned to their home cage and sampling was continued for approximately $2-3 \mathrm{hr}$. Perfusion medium was then substituted with a solution containing $10 \mathrm{~mm}$ 4-aminopyridine, and perfusion was continued for $1 \mathrm{hr}$. At the end of the test the animals were anesthetized and sacrificed as described.

Experiment 3: effects of ethanol withdrawal on CRF-IR release from the amygdala. In this experiment, rats exposed to ethanol diet $(n=9)$ or control diet $(n=8)$ were implanted with guide cannulae 1 week before the experiment. On the testing day, $12 \mathrm{hr}$ prior to the start of sampling, microdialysis probes were secured in the guide cannula under halothane anesthesia. The probe was perfused with ACSF at a rate of $0.7 \mu \mathrm{l} / \mathrm{min}$ overnight. On the next morning, $1 \mathrm{hr}$ before sampling, the perfusion medium was changed to a freshly prepared medium containing anti-CRF serum, and the flow rate was increased to $3.0 \mu \mathrm{l} / \mathrm{min}$. Fractions of $60 \mu \mathrm{l}$ were then collected every $20 \mathrm{~min}$. All experiments started with collection of five basal fractions, during a period of $2 \mathrm{hr}$ in which ethanol diet was available. At the end of this period the bottle containing ethanol diet was removed and replaced by control diet. Perfusion medium was then changed, and perfusion continued at the same flow rate using regular ACSF. Standard ACSF and solution containing anti-CRF serum were substituted every $2 \mathrm{hr}$, and this procedure was repeated four times during the experiment. Thus, CRF-IR Inleasurements were performed over four periods of $2 \mathrm{hr}$ interspersed with nonsampling $2 \mathrm{hr}$ periods over a total of $12 \mathrm{hr}$. The first fraction collected after each change of the perfusion medium was discarded to avoid carryover effects from dialysate remaining in the tubing dead volume. The fourfraction collection periods corresponded to the $2-4 \mathrm{hr}, 6-8 \mathrm{hr}$, and 10 $12 \mathrm{hr}$ intervals after withdrawal. At the end of the experiment, rats were perfused with ACSF over night at $0.7 \mu \mathrm{l} / \mathrm{min}$ before sacrifice. During withdrawal each rat was observed for physical signs of withdrawal (Baldwin et al., 1991).

Statistical analysis. The effects of various doses of 4-aminopyridine on CRF release in vitro were analyzed using one-way $\Lambda$ NOV $\Lambda$, while a mixed factorial ANOVA was used to study the interaction of $\mathrm{CoCl} 2$ on 4-aminopyridine-stimulated release. The effect of restraint stress on CRF-IR release in vivo was assessed using onte-way ANOVA for repeated measurements. The data collected in the experiment performed on ethanol-dependent rats were analyzed using a mixed factorial ANOVA with "diet" as between-subject factor and "time of withdrawal" as within-subject factor. In all experiments significant differences among individual means were determined by Tukey's post hoc test.

\section{Results}

\section{Experiment I: in vitro CRF-IR release from amygdala}

Figure 1 shows the effects of 4-aminopyridine on CRF release from slices of amygdala tissues in vitro. Inclusion of 4-aminopyridine in the incubation medium significantly increased CRFIR release in a dose-response fashion $(p<0.01)$. Significant effects were observed at $1.0 \mathrm{~mm}(p<0.05)$ and $10.0 \mathrm{~mm}(p<$ $0.01)$ 4-aminopyridine concentrations, while the lowest dose $(0.1$ $\mathrm{mM}$ ) was without significant effect. In the presence of $\mathrm{CoCl}_{2}$, the stimulating effects of $1.0 \mathrm{mM} \mathrm{4-aminopyridine} \mathrm{were} \mathrm{com-}$ pletely antagonized $(p<0.05)$. These results confirm the $\mathrm{Ca}^{2+}$ dependency of CRF-IR release from slices of rat amygdala in vitro.

\section{Experiment 2: effects of restraint stress on CRF-IR release from the amygdala}

Postmortem anatomical evaluation of the placement of the "active" zone of the microdialysis probes in rats exposed to restraint stress revealed that the target region was an area defined by the lateral component of the Ce and the medial border of the BL (Fig. 2). A graphical representation of the locations of the microdialysis membrane region in the brain of all rats of this experiment is shown in Figure $3 B$. Two rats were not included in the data analysis because of anatomical misplacement of the probe.

Basal and stress-induced CRF-IR levels in dialysate from the amygdala of awake rats over time are shown in Figure $3 A$. Basal CRF-IR dialysate concentrations in undisturbed rats were 1.19 $\pm 0.15 \mathrm{fmol} / 50 \mu \mathrm{l}$. These values represent the mean and the standard error of all the fraction values measured before stress 


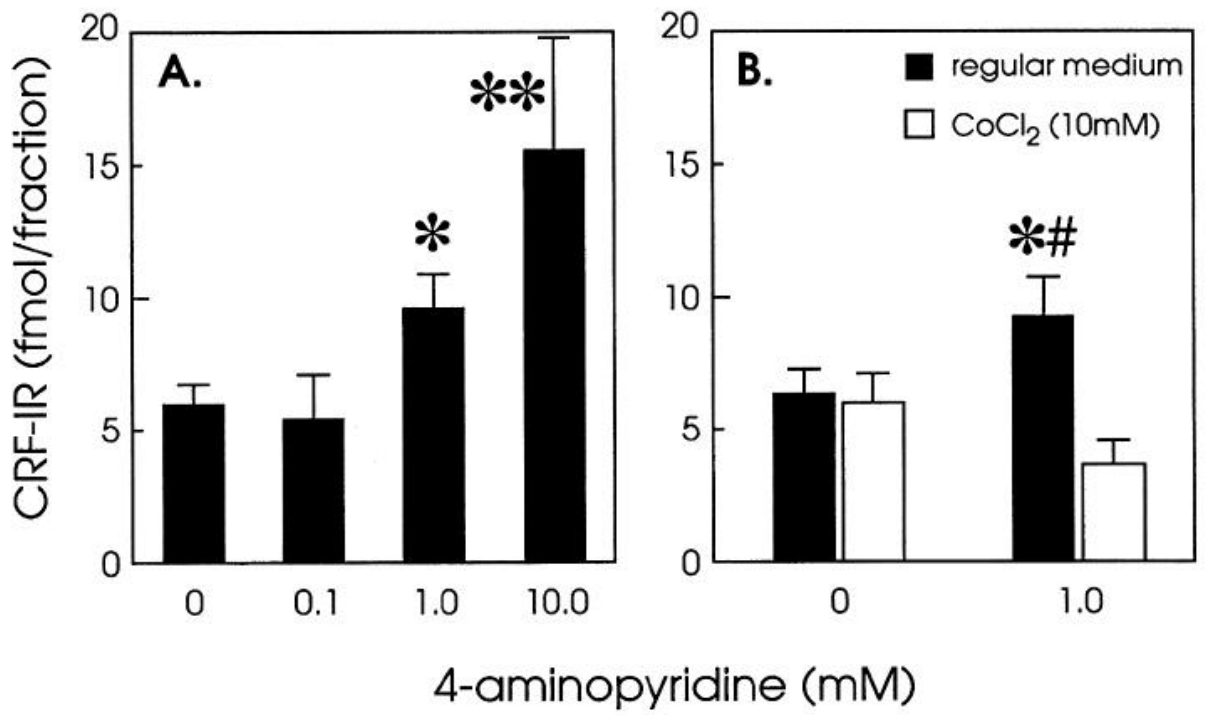

Figure 1. A, Effects of incubation with 4-aminopyridine at different concentrations (mM) on CRF-IR release from slices of the rat amygdala tissue in vitro. Amygdala slices were incubated in regular medium, and then exposed to 4-aminopyridine during the following 20 min interval. Since basal CRF-IR levels did not differ from those measured in the stimulation interval when 4-aminopyridine was absent ( 0 mM), only the results obtained during the stimulation intervals are shown. Each bar represent the mean \pm SEM of four to six rats $(*, p<0.05 ; * *, p<0.01$; vs basal CRF-IR levels, Tukey's test). $B$, Effects of cobalt chloride $\left(\mathrm{CoCl}_{2}\right)$ on CRF-IR release induced by 4-aminopyridine from slices of amygdala tissue in vitro. Basal CRF-IR levels are represented on the left, when 4-aminopyridine was absent, while stimulated CRF-IR levels are shown on the right, in the presence of $1 \mathrm{~mm}$ 4-aminopyridine. Incubation with $10 \mathrm{mM} \mathrm{CoCl}_{2}$ (open bars) abolished the effects of 4-aminopyridine. Each bar represents the mean \pm SEM of five rats ( $*, p<0.05$, stimulated vs basal CRF-IR levels; \#, $p<0.05$; regular medium vs $\mathrm{CoCl}_{2}$ during stimulation).

in all rats. Restraint stress $(20 \mathrm{~min})$ produced a significant increase of CRF-IR dialysate levels to $4.54 \pm 1.33 \mathrm{fmol} / 50 \mu \mathrm{l}(p$ $<0.01$ ). After stress, dialysate CRF-IR levels returned to levels close to the basal values in about $1 \mathrm{hr}$. During the following intervals, perfusion with 4-aminopyridine markedly increased CRF-IR concentrations in the dialysate collected over a $1 \mathrm{hr}$ sampling period $(4.83 \pm 0.92 \mathrm{fmol} / 50 \mu \mathrm{l}, p<0.01)$. All rats in which CRF-IR release was increased by restraint stress also showed significant increases of CRF-IR levels during 4-aminopyridine perfusion. Observation of the rats during the experiment indicated that perfusion with 4-aminopyridine produced behavioral signs of increased arousal, inducing episodes of locomotor activity alternated with periods of immobility, and occasional limbic seizures.
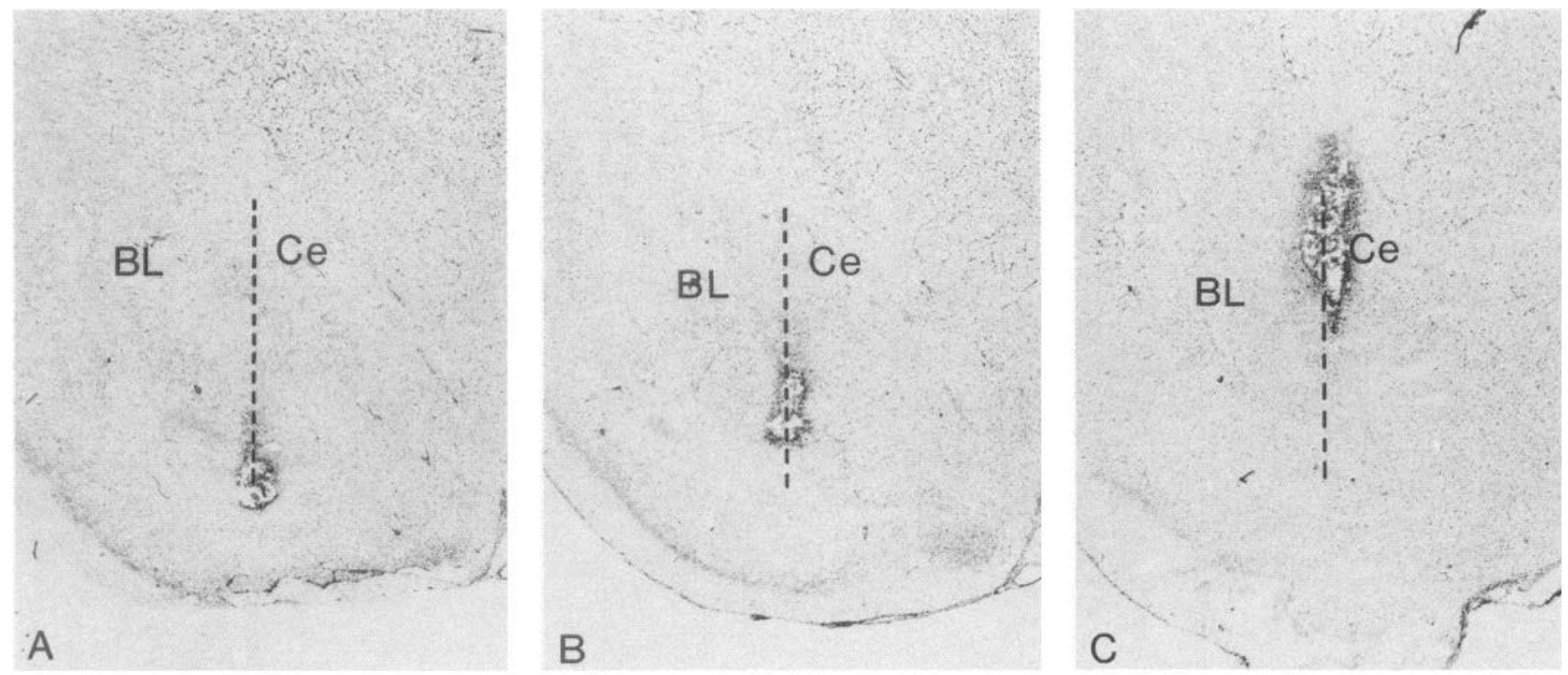

Figure 2. Anatomical estimation of the "active" zone of microdialysis probes implanted in rats and aimed at the amygdala. A series of consecutive brain sections bearing the trace of the microdialysis probe were stained with cresyl violet. Sections were selected on the basis of the most ventral location of the probe tip. The sections with the deepest trace was selected $(A)$, and a segment of $2 \mathrm{~mm}$ then drawn vertically, tracing the estimated location of the active zone (broken line). The same procedure was performed on more rostral sections, maintaining the stereotactic and anatomical alignment $(B$ and $C)$. From this analysis the estimated region of location of the microdialysis membrane was an area defined by the lateral component of the central nucleus of the amygdala $(\mathrm{Ce})$ and the medial border of the basolateral nucleus of the amygdala $(B L)$. 

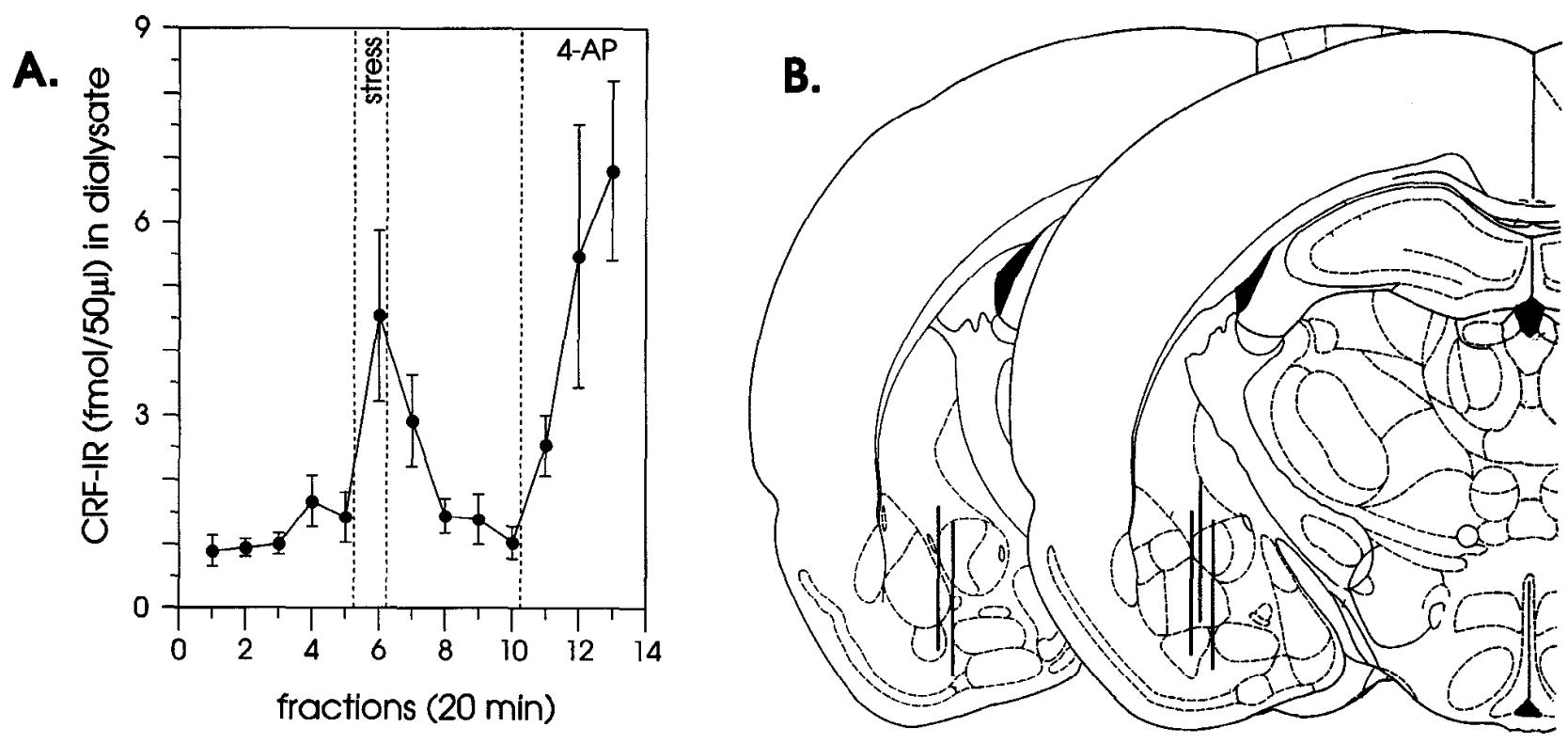

Figure 3. A, Effects of restraint stress $(20 \mathrm{~min}$ ) and 4-aminopyridine (4-AP, $10 \mathrm{~mm}$ ) perfusion on CRF-IR levels as measured by intracranial microdialysis in the rat amygdala. Fractions were collected every $20 \mathrm{~min}$. CRF-IR levels measured during stress and 4-AP were significantly different from basal levels $(p<0.05)$. B, Distribution of the anatomical localizations of the "active" zone of microdialysis probes according to anatomical trace analysis carried out as described in Figure 2. Only microdialysis probe traces of rats included in the restraint stress experiment are reported $(n=5)$.

\section{Experiment 3: effects of ethanol wilhdrawal on CRF-IR release from the amygdala}

Exposure to the ethanol diet produced moderately high BAL levels in exposed rats $(126 \pm 13 \mathrm{mg} \%)$. No differences in body weight between the ethanol and control diet groups as assessed the day before the experiment was noted. Observation of experimental rats during microdialysis experiments showed that, during the 6-12 hr period of withdrawal, ethanol-exposed rats were awake most of the time, displayed low levels of spontaneous locomotor activity, exhibited occasional body tremor and stiffness of the tail. Conversely, control rats were frequently sleeping, and nu body tremor or stiffness of the tail were ob- served. Seven rats (three control and four ethanol dependent rats) were excluded from further analysis because of surgical failure $(n=2)$, probe disconnection, or membrane rupture $(n=$ $2)$, radioimmunoassay errors $(n=1)$, or inadequate $\operatorname{BAL}(n=$ 2 ), resulting a sample of five ethanol-dependent rats and five control rats. The initial fractions collected during the $2-4 \mathrm{hr}$ period of three rats included in the experiment were not available for assay, and therefore this collection interval was excluded from the analysis. Postmortem anatomical evaluation of microdialysis probe placements indicated that the tips were located between the $\mathrm{Ce}$ and the BL (Fig. 4), as observed in rats exposed to restraint stress.

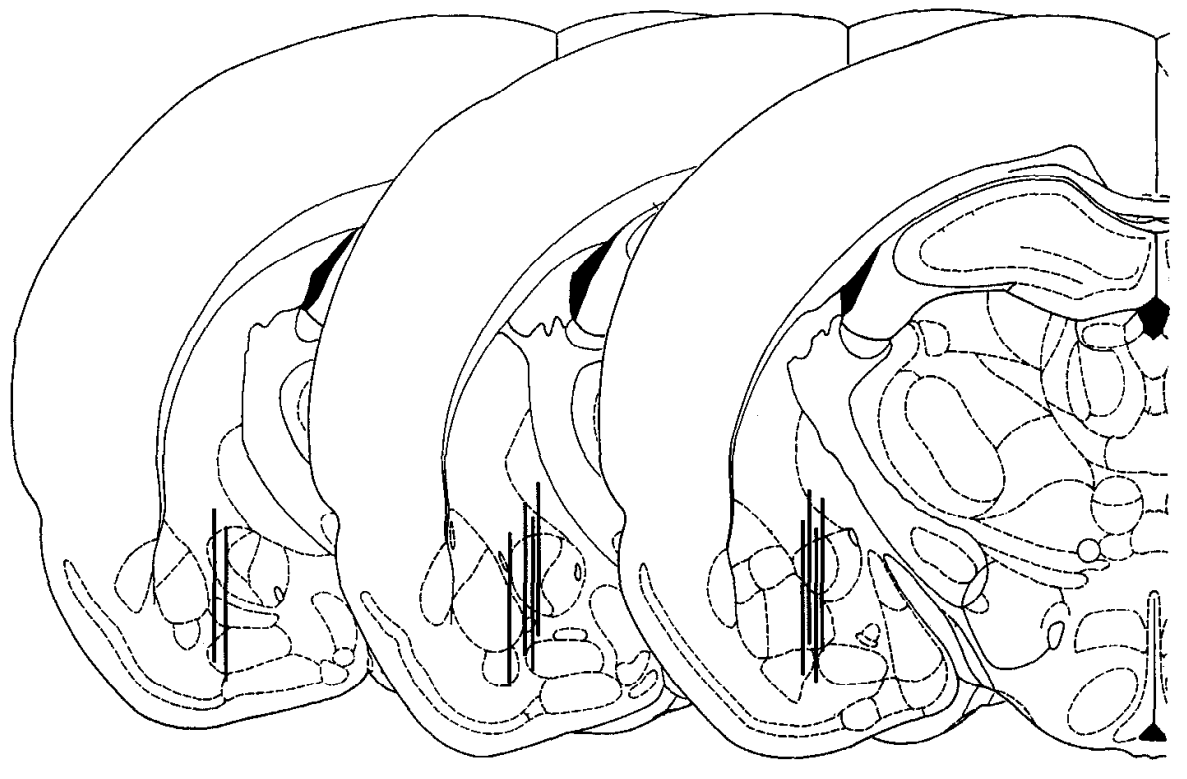

Figure 4. Anatomical localizations of the "active" zone of microdialysis probes according to anatomical trace analysis carried out as described in Figure 2 . Only the microdialysis probe traces of rats included in the ethanol experiment are reported $(n-10)$. 
Figure 5. Effects of ethanol withamygdala as determined by microdialysis. Dialysate was collected over four $2 \mathrm{hr}$ periods regularly alternated with nonsampling $2 \mathrm{hr}$ periods. The four sampling periods correspond to the basal collection (before removal of ethanol), and 2-4 hr, 6-8 hr, and 10$12 \mathrm{hr}$ after withdrawal. Fractions were collected every $20 \mathrm{~min}$. Data are represented as mean \pm SEM $(n=$ 5/group). ANOVA confirmed significant differences between the two groups over time $(p<0.05)$. drawal on CRF-IR levels in the rat

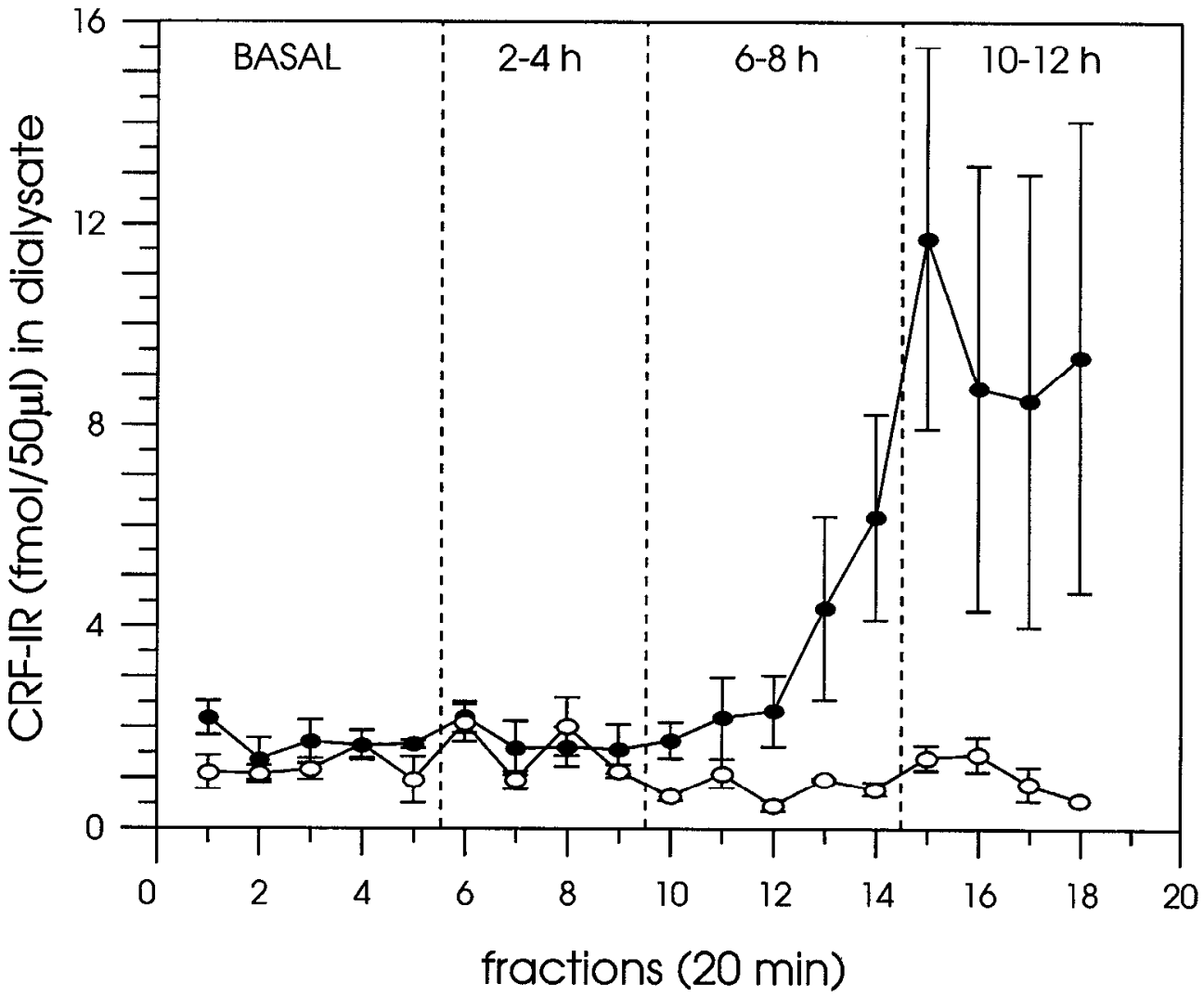

The results of the microdialysis experiments are shown in Figure 5. The average basal CRF-IR levels measured in dialysate from the amygdala were $1.30 \pm 0.19 \mathrm{fmol} / 50 \mu \mathrm{l}$ and $2.11 \pm$ $0.43 \mathrm{fmol} / 50 \mu \mathrm{l}$ in control diet and ethanol diet-exposed rats, respectively. Although this difference was not statistically significant, ANOVA indicated that the overall difference between the two treatment groups during withdrawal was significant $[F(1,8)=7.65, p<0.05]$. Accordingly, there was a significant time-dependent increase in CRF-IR levels measured in dialysate $(p<0.01)$. This effect over time was mainly due to the increase of CRF-IR levels measured in ethanol-exposed rats during withdrawal, as indicated by significant "treatment $X$ time" interaction $(p<0.01)$. Post hoc analysis of simple effects showed that the two groups were significantly different during the $10-12 \mathrm{hr}$ period of withdrawal $(p<0.01)$, while only marginally significant increases in CRF-IR levels were obtained during the 6-8 hr period of withdrawal $(0.10>p>0.05)$.

\section{Discussion}

The results presented in this article confirm and extend previous observations that depolarizing agents can induce CRF-IR release from slices of rat amygdala in vitro in a $\mathrm{Ca}^{2+}$-dependent manner. The stimulant action of 4-aminopyridine on CRF-IR release was also present in awake rats studied with intracranial microdialysis. More interestingly, a transient increase of CRF-IR release was observed when rats implanted with a microdialysis probe in the amygdala were exposed to restraint stress for $20 \mathrm{~min}$. In contrast, a progressive and prolonged increase of CRF-IR release was measured in ethanol-dependent rats during ethanol withdrawal, with a time course corresponding to the emergence and progression of behavioral signs of withdrawal. These findings indicate that CRF-IR can be released from the rat amygdala in response to stress produced by exogenous or endogenous stimuli that result in increased arousal and emotionality.

The origin of CRF-IR measured in the present experiments is likely to be in the nerve terminals of the Ce. This interpretation is based on immunocytochemical evidence that shows a dense plexus of positive neurons, fibcrs, and terminals in the Ce (Sakanaka et al., 1988; Cassel and Gray, 1989; Gray, 1990). The assessment of microdialysis probe locations within the amygdala indicated that CRF-IR levels in perfusate were detectable when the probe was placed in close proximity to the $\mathrm{Ce}$. In two cases of anatomical misplacement, in which the active part of the probe was located in the cortex, the levels of CRF-IR were almost undetectable (data not shown). The anatomical specificity of CRF-IR measurement with microdialysis in the rat brain was previously studied in anesthetized rats. CRF-IR levels were undetectable in perfusate from probes placed in the upper third ventricle and dorsal striatum, while CRF-IR levels of about 1 fmol/50 $\mu \mathrm{l}$ were measured in the mediobasal hypothalamus and Ce (Merlo Pich et al., 1993). CRF-IR release from the mediobasal hypothalamus was also measured in anesthetized rats (Gabr et al., 1994), and in awake rats using the push-pull cannula (Ixart et al., 1987). In both present experiments involving awake rats, basal dialysate CRF-IR levels were within the range measured in the perfusate from the amygdala of anesthetized rats.

The synaptic origin of CRF-IR is further supported by the observation of enhanced CRF-IR release by depolarizing stimuli, and its dependency upon $\mathrm{Ca}^{2+}$ availability. $\mathrm{Ca}^{2+}$-dependent $\mathrm{K}^{+}$induced release of CRF has been demonstrated in amygdala primary culture from embryonic explants (Cratty and Brikle, 1994), in slices of amygdala tissue from adult rat brain (Smith et al., 1986), and in perfusate from a microdialysis probe located in the Ce of anesthetized rats (Merlo Pich et al., 1993; Richter et 
al., submitted). In the present work, these observations were extended by showing that also the $\mathrm{K}^{+}$-channel blocker 4 -aminopyridine stimulates CRF-IR release in the amygdala. CRF-IR increases produced by 4-aminopyridine were completely blocked by the $\mathrm{Ca}^{2+}$ antagonist $\mathrm{CoCl}_{2}$ in vitro. Preliminary observations indicate that the same blocking effect of $\mathrm{CoCl}_{2}$ was present in anesthetized rats implanted with microdialysis probes in the amygdala ( $R$. Richter, unpublished data). It is worth to note that the 4-aminopyridine-dependent release of CRF-IR may not be a direct effect. In fact, 4-aminopyridine is known to release norepinephrine and acetylcholine in vitro (Drukarch et al., 1989; Heemskerk et al., 1990). Since norepinephrine or acetylcholine can produce CRF-IR release from the CNS neurons (Tsagarakis et al., 1988; Hu et al., 1992), it cannot be excluded that these or other neurotransmitters mediate the effects of 4-aminopyridine on CRF release within the amygdala.

Previous findings of high concentrations of CRF binding sites within the amygdaloid nuclei, particularly in the basolateral nucleus (BL) (De Souza, 1987; Perrin et al., 1993), strongly suggest a rolc for locally relcased CRF-IR on amygdaloid ncuron activity. In brain slice preparations CRF produces postsynaptic depolarization in most of amygdala cells (Eberly et al., 1983; Rainnie et al., 1992), but presynaptic inhibitory effects on CRFIR neurons have also been proposed (Wiersma et al., 1993). CRF binding sites are located on the perikarya, dendrites, and terminals of peptide-containing medium spiny neurons of the $\mathrm{Ce}$, including CRF-IR neurons. Incidentally, receptors on CRF-IR neurons may represent autoreceptors that regulate CRF-IR release, locally (Wiersma et al., 1993) or in their projection fields in hypothalamic and brainstem nuclei. Thus, a rise in extracellular CRF-IR levels in the $\mathrm{Ce}$ may contribute to activate peptidecontaining medium spiny neurons of the amygdala, activation recently demonstrated using Fos immunostaining technique in rats exposed to restraint stress (Honkaniemi, 1992). However, by acting on autoreceptors, CRF may also participate in the shutdown of CRF-IR release from CRF-IR neurons. To further complicate the picture of the role of CRF in the amygdala, BL neurons are also likely to be affected by CRF-IR. Since microdialysis experiments have shown that CRF-IR levels increased in a sampling region between $\mathrm{Ce}$ and $\mathrm{BL}$ during stress, it is reasonable to suggest that locally released CRF-IR can diffuse and modulate also BL neurons, possibly in a nonsynaptic way (Fuxe and Agnati, 1991). Since BL neurons massively project to $\mathrm{Ce}$, but Ce neurons do not project to BL (McDonald, 1992), it is possible that CRF-IR diffusing from $\mathrm{Ce}$ can retrogradely affect BL neurons, providing a local nonsynaptic feedback mechanism. All these observations point to a complex modulatory role of CRF within the amygdala.

The present results complement a series of behavioral experiments aimed to understand the involvement of CRF in emotionality. When the CRF antagonist $\alpha \mathrm{CRF}(9-41)$ was microinjected within the amygdala of rats exposed to social stress, a dose-dependent decrease of the stress-induced anxiogenic-like effect was observed (Heinrichs et al., 1992). Attenuation of stress-induced immobility was also produced by intra-amygdala administration of $\alpha \operatorname{CRF}(9-41)$ in the pM range (Swiergiel et al., 1993). Thus, it may be concluded that CRF in the amygdala mediates the emotional response to stress exposure (but see also Liang et al., 1992a,b).

The results of the present experiments performed in ethanoldependent rats during ethanol withdrawal partially support this hypothesis. Chronic ethanol exposure has been associated with emotional hyperactivity in rodents and humans (Cooper et al., 1979; Glue and Nutt, 1990). Stress-like effects produced by withdrawal from chronic ethanol have been previously studied in rats using the social interaction test (File et al., 1989) and the elevated plus-maze (Baldwin et al., 1991). In these experiments, significant withdrawal signs are ohserved approximately 8-10 $\mathrm{hr}$ after ethanol withdrawal. Recent work has shown that intraamygdala administration of $\alpha \operatorname{CRF}(9-41)$ blocks the anxiogeniclike effects of ethanol withdrawal in the elevated plus-maze 8 hr after withdrawal (Rassnick et al., 1993). Interestingly, this period corresponds to the rise in CRF-IR dialysate levels from amygdala observed in the present experiment. The most intense effects of withdrawal on CRF-IR release were observed at 10$12 \mathrm{hr}$. The peak of CRF-IR levels were two to three times higher that the peak effect in rats exposed to restraint stress, suggesting an increased activity of CRF-IR neurons in the amygdala. In rats chronically exposed to ethanol, increased sensitivity to the locomotor stimulating effects of $\mathrm{CRF}$ is also reported (Ehlers and Chaplin, 1987).

The mechanisms involved in the enhanced CRF-IR release are not known. Since acute administration of ethanol exerts anxiolytic-like effects, prolonged exposure to ethanol may produce adaptive changes in central neurons to counteract this inhibitory effect (Pohorecky, 1981; Koob and Bloom, 1988). According to this hypothesis, the absence of ethano! during withdrawal would produce a rebound activation of previously inhibited neurons, leading to their hyperactivity (Glue and Nutt, 1990). The increased CRF release measured in the amygdala of dependent rats during withdrawal may represent such a mechanism, in that inhibition of CRF neurons of the Ce by chronic ethanol may result in a downregulation of inhibitory receptors, such as CRF autoreceptors or GABA/benzodiazepine receptors. GABA/benzodiazepine receptors activity is known to be reduced by chronic ethanol exposure (Morrow et al., 1988). Since both Ce and BL neurons contain a very high density of GABA/benzodiazepine binding sites (Niehoff and Kuhar, 1988), it can bc surmiscd that CRF-IR neurons are normally under the inhibitory effects of GABAergic transmission. Therefore, the reduced tonic influence of GABAergic transmission in chronic ethanol exposed rats may result in disinhibition of CRF-IR neurons.

A third possible substrate mediating the CRF-IR release in the amygdala during ethanol withdrawal is represented by monoamines, in particular, norepinephrine. In both situations of stress and ethanol withdrawal the triggering signal for CRF-IR release may be due to norepinephrine released from the terminals innervating the $\mathrm{Ce}$ (Fallon et al., 1988; Gavin, 1990). A recent microdialysis experiment (Tanaka et al., 1991) showed that the temporal profile of norepinephrine release from the amygdala of rats exposed to $20 \mathrm{~min}$ restraint stress closely matches that of CRF-IR described in the present work. In vitro norepinephrine evokes CRF-IR release from hypothalamic neurons (Tsagarakis et al., 1988; Hu et al., 1992), while microdialysis experiments show that CRF produces norepinephrine release from nerve terminals in prefrontal cortex and hypothalamus (Lavicky and Dunn, 1993), suggesting the existence of a reciprocal stimulating interaction between CRF and norepinephrine. Although the relevance of central norepinephrine in anxiety is still under debate, some of the behavioral effects produced by stress and ethanol withdrawal involve adrenoreceptor mediation (Berridge and Dunn, 1989; Glue et al., 1989; Soderpalm and Engel, 1990).

In conclusion, a recently validated method to measure CRFIR release with microdialysis in freely moving rats was used to 
investigate the effects of restraint stress and ethanol withdrawal on CRF-IR release from the amygdala. The time course of the enhancing effects on CRF-IR release induced by restraint stress and ethanol withdrawal parallels the appearance of anxiogenic behavioral effects. Together, these results suggest that CRF-IR neurons of the amygdala participate in mediating the emotional effects of restraint stress and ethanol withdrawal.

\section{References}

Antoni FA (1986) Hypothalamic control of adrenocorticotropin secretion: advances since the discovery of 41-residue corticotropin-releasing factor. Endocr Rev 7:331-378.

Baldwin HA, Rassnick S, Rivier J, Koob G, Britton KT (1991) CRF antagonist reverses the "anxiogenic" response to ethanol withdrawal in the rat. Psychopharmacology (Berlin) 103:227-232.

Berridge CW, Dunn AJ (1989) Restraint-stress-induced clanges in exploratory behavior appear to be mediated by norepinephrine-stimulated release of CRF. J Neurosci 9:3513-3521.

Bohemer G, Schmidt K, Ramsbott M (1990) Effects of corticotropinreleasing factor on central respiratory activity. Eur J Pharmacol 182: 405-411.

Britton KT, Morgan J, Rivier J, Vale W, Koob GF (1985) Chlordiazepoxide attenuates response suppression induced by corticotropin-releasing factor in the conflict test. Psychopharmacology (Berlin) 86: 170-174.

Britton KT, Lee G, Vale W, Rivier J, Koob GF (1986) Corticotropinreleasing factor antagonists block activating and "anxiogenic" action of CRF in the rat. Brain Res 369:303-306.

Brown MR, Fisher LA, Spiess J, Rivier C, Rivier J, Vale W (1982) Corticotropin-releasing factor: actions on sympathetic nervous system and metabolism. Endocrinology 111:928-931.

Calogero AE, Bernardini R, Margioris AN, Bagdy G, Gallucci WT, Munson PJ, Tamarkin L, Tomai TP, Brady L, Gold PW, Chrousos GP (1989) Effects of serotonergic agonists and antagonists on rat hypothalamic corticotropin-releasing hormone secretion in vitro. Peptides 10:189-200.

Cassell MD, Gray TS (1989) Morphology of peptide-immunoreactive ncurons in the rat ecntral nucleus of the amygdala. J Comp Neurol 281:320-333.

Chappel PB, Smith MA, Kilts CD, Bissette G, Richtie J, Anderson C, Nemeroff CB (1986) Alteration of corticotropin-releasing factor-like immunoreactivity in discrete rat brain regions after acute and chronic stress. J Neurosci 6:2908-2914.

Cooper BR, Viik K, Ferris RM, White HL (1979) Antagonism of the enhanced susceptibility to audiogenic seizures during alcohol withdrawal in the rat by GABA and GABA-mimetic agents. J Pharmacol Exp Ther 208:396-403.

Cratty MS, Brikle DL (1994) Depolarization-induced release of corticotropin-releasing factor (CRF) in primary neuronal cultures of the amygdala. Neuropeptides 26:113-121.

Cummings S, Elde R, Ellis J, Lindall A (1983) Corticotropin-releasing factor immunoreactivity is widely distributed within the central nervous system of the rat: an immunocytochemical study. J Neurosci 3:1355-1368.

Davis M (1986) Pharmacological and anatomical analysis of fear conditioning using the fear-potentiated startle paradigm. Behav Neurosci 100:814-824.

Davis M (1992) The role of amygdala in fear and anxiety. Annu Rev Neurosci 15:353-375.

De Sota GB, O'Donnell WE, Allred LJ, Lopez CE (1985) Symptomatology in alcoholics at various stages of abstinence. Alcohol Clin Exp Res 9:505-512.

De Souza EB (1987) Corticotropin-releasing factor receptors in the rat central nervous system: characterisation and regional distribution. $\mathrm{J}$ Neurosci 7:88-100.

Drukarch B, Kits KS, Leysen JE, Schepens E, Stoof JC (1989) Restricted usefulness of tetraethyl ammonium and 4-aminopyridine for the characterisation of receptor-operated $\mathrm{K}^{+}$-channels. $\mathrm{Br} \mathrm{J}$ Pharmacol 98:113-118.

Dunn AJ, Berridge CW (1990) Physiological and behavioral responses to corticotropin-releasing factor administration: is CRF a mediator of stress responses? Brain Res Rev 15:71-100.
Dunn AJ, File SE (1987) Corticotropin-releasing factor has an anxiogenic action in the social interaction test. Horm Bchav 21:193-202.

Dunn JD, Whitener J (1986) Plasma corticosterone responses to electrical stimulation of the amygdaloid complex: cytoarchitectural specificity. Neuroendocrinology 42:211-217.

Eberly LB, Dudley CA, Moss RL (1983) Iontophoretic mapping of corticotropin-releasing factor (CRF) sensitive neurons in the rat forebrain. Peptides 4:837-841.

Ehlers CL, Chaplin RI (1987) Chronic ethanol exposure potentiates the locomotor activating effects of corticotropin-releasing factor (CRF) in rats. Regul Pept 19:345-354.

Fallon JH, Koziell DA, Moore RY (1978) Catecholamine innervation of the basal forebrain. II Amygdala, suprarhinal cortex and entorhinal cortex. J Comp Neurol 180:509-531.

File SE, Baldwin HA, Hitchcott PK (1989) Flumazenil but not nitrendipine reverses the increased anxiety during ethanol withdrawal in the rat. Psychopharmacology (Berlin) 98:252-24.

Freund G (1969) Alcohol withdrawal syndrome in mice. Arch Neurol 21:315-320.

Fuxe K, Agnati LF, eds (1991) Volume transmission in the brain. In: Advances in neuroscience, Vol 1, Novel mechanisms for neural transmission. New York: Raven.

Gabr RW, Gladfelter WE, Birke DL, Azzaro AJ (1994) In vivo microdialysis of corticotropin-releasing factor (CRF): calcium dependence of depolarization-induced neurosecretion of CRF. Neurosci Lett 169: 63-67.

Galvin GB (1990) Stress and monoamines: a review. Neurosci Biobehav Rev 9:233-243.

Glue P, Nutt D (1990) Overexcitement and disinhibition. Dynamic neurotransmitter interaction in alcohol withdrawal. Br J Psychiatry 157: $491-499$.

Gray TS (1990) The organization and possible function of amygdaloid corticotropin-releasing factor pathway. In: Corticotropin-releasing factor: basic and clinical studies of a neuropeptide (De Souza EB, Nemeroff CB, eds), pp 53-68. Boca Raton, FL: CRC.

Gray TS, Magnuson DJ (1987) Neuropeptide neuronal efferents from the bed nucleus of the stria terminalis and central amygdaloid nucleus to the dorsal vagal complex in the rat. J Comp Neurol 262:365-374.

Gray TS, Magnuson DJ (1992) Peptide immunoreactive neurons in the amygdala and the bed nucleus of the stria terminalis project to the midbrain central gray in the rat. Peptide 13:451-460.

Hauger RL, Millan MA, Catt KJ, Aguilera G (1987) Differential regulation of brain and pituitary corticotropin-releasing factor receptors by corticosterone. Endocrinology 120:1527-1533.

Heemskerk FM, Schrama LH, Gianotti C, Spiereburg H, Versteeg DH, De Graan PN, Gispen WH (1990) 4-Aminopyridine stimulates B-50 (GAP43) phosphorylation and ${ }^{3} \mathrm{H}$-noradrenaline release in rat hippocampal slices. J Neurochem 54:863-869, 1990.

Heinrichs SC, Merlo Pich E, Miczek K, Britton KT, Koob GF (1992) Corticotropin-releasing factor antagonist reduces emotionality in socially defeated rats via direct neurotropic action. Brain Res 581:190197.

Honkaniemi J (1992) Colocalization of peptide- and tyrosine hydroxylase-like immunoreactivity with Fos-immunoreactive neurons in rat central amygdaloid nucleus atter immobilization stress. Brain Res 598:107-113.

Hu SB, Tannahill LA, Lightman SL (1992) Mechanisms of noradrenaline- mediated corticotropin-releasing factor- 41 release from cultured fetal hypothalamic cells. Neuroendocrinology 56:712-718.

Imaki T, Nahan JL, Rivier C, Sawchenko, PE, Vale W (1991) Differential regulation of corticotropin-releasing factor mRNA in rat brain regions by glucocorticoids and stress. J Neurosci 11:585-599.

Iwata J, Chida K, Lc Doux JE (1987) Cardiovascular responses elicited by stimulation of neurons in the central amygdaloid nucleus in awake but not anesthetized rats resemble conditioned emotional responses. Brain Res 418:183-188.

Ixart G, Barbanel G, Conte-Devoix B, Grino M, Olivier C, Assenmacher I (1987) Evidence for basal and stress-induced release of corticotropin-releasing factor in the push-pull cannulated median eminence of conscious free-moving rats. Neurosci Lett 74:85-89.

Kalin NH, Sherman JE, Takahashi LK (1988) Antagonism of endogenous CRH systems attenuates stress-induced freezing behavior in rats. Brain Res 457:130-135

Koob GF, Bloom FE (1985) Corticotropin releasing factor and behavior. Fed Proc 44:259-263. 
Koob GF, Bloom FE (1988) Cellular and molecular mechanisms of drug dependence. Sciencc 242:715-723.

Koob GF, Heinrichs SC, Merlo Pich E, Menzaghi F, Baldwin H, Miczek K, Britton KT (1993) Corticotropin-releasing factor in behavioral response to stress. In: Ciba Foundation symposium 172, Corticotropin-releasing factor, pp 277-289. Chichester: Wiley.

Lavicky J, Dunn AJ (1993) Corticotropin releasing-factor stimulates catecholamine release in hypothalamus and prefrontal cortex in freely moving rats as assessed with microdialysis. J Neurochem 60:602612.

Le Doux JA, Iwata J, Cicchetti P, Reis DJ (1988) Different projections of the central amygdaloid nucleus mediate autonomic and behavioral correlates of conditioned fear. J Neurosci 8:2517-2529.

Liang KC, Melia KR, Miserendino MJD, Falls WA, Campeau S, Davis M (1992a) Corticotropin-releasing factor: long lasting facilitation of the acoustic startlc reflex. J Ncurosci 12:2303-2312.

Liang KC, Melia KR, Campeau S, Falls WA, Miserendino MJD, Davis $M$ (1992b) Lesion of the central nucleus of the amygdala, but not the paraventricular nucleus of the hypothalamus, block the excitatory effects of corticotropin-releasing factor on the acoustic startle reflex. J Neurosci 12:2313-2320.

Maidment NT, Brumbaugh DR, Rudolph VD, Erdely E, Evans CJ (1989) Microdialysis of extracellular endogenous opioid peptides from rat brain in vivo. Neuroscience 33:549-557.

McDonald AJ (1992) Cell types and intrinsic connections of the amygdala. In: Corticotropin-releasing factor: basic and clinical studies of a neuropeptide (De Souza EB, Nemeroff CB, eds), pp 67-96. Boca Raton, FL: CRC.

Menzaghi F, Howard RL, Heinrichs SC, Vale W, Rivier J, Koob GF (1994) Characterization of a novel and potent corticotropin-releasing factor antagonist in rats. J Pharmacol Exp Ther 269:564-572.

Merlo Pich E, Koob GF, Heilig M, Menzaghi F, Vale W, Weiss F (1993) Corticotropin-releasing factor release from the mediobasal hypothalamus as measured by microdialysis. Neuroscience 55:695-707.

Morrow AL, Suzdak PD, Karanian JW, Paul SM (1988) Chronic ethanol administration alters gamma-aminobutyric acid, pentobarbital and ethanol-mediated ${ }^{36} \mathrm{Cl}$-uptake in cerebral cortical synaptoneurosome. J Pharmacol Exp Ther 246:158-164

Nemeroff CB (1992) New vistas in neuropeptide research in neuropsychiatry: focus on corticotropin-releasing factor. Neuropsychopharmacology 6:69-75.

Niehoff DL, Kuhar MJ (1988) Benzodiazepine receptors: localization in the rat amygdala. $\mathbf{J}$ Neurosci 3:2091-2097.

Paxinos G, Watson C (1986) The rat brain in stereotaxic coordinates. New York: Academic.

Perrin MH, Donaldson CJ, Chen R, Lewis KA, Vale W (1993) Cloning and functional expression of a rat brain corticotropin-releasing factor (CRF) receptor. Endocrinology 133:3058-3061.

Plotsky PM (1991) Pathways to the secretion of adrenocorticotropin: a view from the portal. J Neuroendocrinol 3:1-9.

Pohorecky LA (1981) The interaction of alcohol and stress. A review. Neurosci Biobehav Rev 5:209-229.

Raber J, Merlo Pich E, Koob GF, Bloom FE (1994) IL-1 $\beta$ potentiates the acetylcholine-induced release of vasopressin from the hypothalamus in vitro, but not from the amygdala. Neuroendocrinology 59: 208-217.

Rainnie DG, Fernhout BJH, Shinnick-Gallagher P (1992) Differential actions of corticotropin-releasing factor on basolateral and central amygdaloid neurons in vitro. J Pharmacol Exp Ther 263:846:858.

Rassnick S, Heinrichs SC, Britton KT, Koob GF (1993) Microinjection of a corticotropin-releasing factor antagonist into the central nucleus of the amygdala reverses anxiogenic-like effects of ethanol withdrawal. Brain Res 605:25-32.
Rivier C, Browstein M, Spiess J, Rivier J, Vale W (1982) In vivo corticotropin-releasing factor induced secretion of adrenocorticotropin, $\beta$-endorphin and corticosterone. Endocrinology 110:272-278.

Rivier C, Imaki T, Vale W (1990) Prolonged exposure to alcohol: effect on CRF mRNA levels, and CRF- and stress-induced ACTH secretion in the rat. Brain Res 520:1-5.

Sakanaka M, Shibasaki T, Lederis K (1988) Corticotropin-releasing factor immunoreactivity in the rat brain as revealed by a modified cobalt-glucose oxydase-diaminobenzidine method. J Comp Neurol 260:256-298.

Sananes CB, Davis M (1992) $N$-methyl-D-aspartate lesions of the lateral and basolateral nuclei of the amygdala block fear-potentiated startle and shock sensitization startle. Behav Neurosci 106:72-80.

Shibata K, Kataoka Y, Yamashita K, Ueki S (1986) An important role of the central nucleus of the amygdala and mammillary body in the mediation of conflict behavior in rats. Brain Res 372:159-162.

Smith MA, Bissette G, Slotnik TA, Knight TL, Nemeroff CB (1986) Release of corticotropin-releasing factor from rat brain regions in vitro. Endocrinology 118:197-2001.

Soderpalm B, Engel JA (1990) Biphasic effect of clonidine on conflict behavior: involvement of different alpha-adrenoreceptors. Pharmacol Biochem Behav 30:471-477

Swanson LW, Mogenson GJ (1985) Neural mechanisms for the functional coupling of autonomic, endocrine and somatosensory response in adaptive behavior. Brain Res Rev 3:1-34.

Swanson LW, Sawchenko PE, Rivier J, Vale W (1983) The organization of ovine corticotropin-releasing factor (CRF) immunoreactive cells and fibers in the rat brain: an immunocytochemical study. Neuroendocrinology $36: 165-186$.

Swerdlow NR, Britton KT, Koob GF (1989) Potentiation of acoustic startle by corticotropin-releasing factor (CRF) and by fear are both reversed by alpha-helical CRF(9-41). Neuropsychopharmacology $2: 285-292$.

Swiergiel AH, Takahashi LK, Kalin (1993) Attenuation of stress-induced freezing by antagonism of corticotropin-releasing factor receptors in the central amygdala in the rat. Brain Res 623:229-234.

Tabakoff B., Jaffe RC, Ritzmann RF (1978) Corticosterone concentration in mice during ethanol drinking and withdrawal. J Pharm Pharmacol 30:371-374.

Takahashi LK, Kalin NH, Vanden Burgt JA, Sherman JE (1989) Corticotropin-releasing factor modulates defensive withdrawal and exploratory behavior in rats. Behav Neurosci 103:648-654.

Tanaka T, Yokoo H, Mizoguchi K, Yoshida M, Tsuda A, Tanaka M (1991) Noradrenaline release in the rat amygdala is increased by stress: studies with intracerebral microdialysis. Brain Res 544:174176.

Tsagarakis S, Holly JMP, Rees LH, Besser GM, Grossman A (1988) Acetylcholine and noradrenaline stimulate the release of corticotropin-releasing factor from the rat hypothalamus in vitro. Endocrinology 123:1962-1969.

Vale W, Speiss J, Rivier C, Rivier J (1981) Characterization of a 41 residue ovine hypothalamic peptide that stimulates the secretion of corticotropin and beta-endorphin. Science 213:1394-1397.

Vale W, Vaugham J, Yamamoto G, Bruhn T, Douglas T, Dalton D, Rivier C, Rivier J (1983) Assay of corticotropin-releasing factor. Methods Enzymol 193:565-577.

Valentino RJ, Foote SL (1988) Corticotropin-releasing factor increases tonic but not sensory-evoked activity of noradrenergic locus coeruleus neurons in unanesthetized rats. J Neurosci 8:1016-1025.

Wiersma A, Bous B, Koolhaas JM (1993) Corticotropin-releasing hormone microinfusion in the central amygdala diminishes a cardiac parasympathetic outflow under stress-free condition. Brain Res 625 : 219-227. 